\title{
Development of monthly seawater intrusion vulnerability assessment method using GALDIT
}

\author{
Il hwan Kim ${ }^{1}$, IL-Moon Chung ${ }^{1}$, and Sun Woo Chang ${ }^{1}$ \\ ${ }^{1}$ Korea Institute of Civil Engineering and Building Technology
}

April 10, 2021

\begin{abstract}
Accurate diagnoses of vulnerability of seawater intrusion (SWI) into aquifers are required to ensure sustainable utilization of groundwater resources in coastal areas. GALDIT was selected to assess the SWI vulnerability on western coastal areas of South Korea. Climate change trends are updated every year. The existing GALDIT method has various scores to express the changing observed values. However, they are limited because of their sensitivity in the assessment of regional characteristics or climatic change due to low weight flexibility. Therefore, this study assessed vulnerability to SWI by classifying the existing GALDIT into static and dynamic parameters. The static parameters include groundwater occurrence $(\mathrm{G})$, aquifer hydraulic conductivity (A), and distance from the shore (D), whereas the dynamic parameters include height to groundwater level above sea level (L), impact of existing status of seawater intrusion (I), and aquifer thickness (T). The monthly mean was used as the dynamic index to reflect monthly variations. To indicate the temporal trend of parameter $\mathrm{L}$ was calculated based on the data observed at the sea level station adjacent to the groundwater level station. To sensitively reflect the monthly changes in values, the range of scores was divided into 10 parts. The calculated GALDIT index showed that the most vulnerable month was September. In the progress of SWI, vulnerability was assessed monthly to highlight the differences in parameters that fluctuate seasonally. The proposed method can be used to apply intensive countermeasures to vulnerable sites and build an operation plan considering the vulnerability period.
\end{abstract}

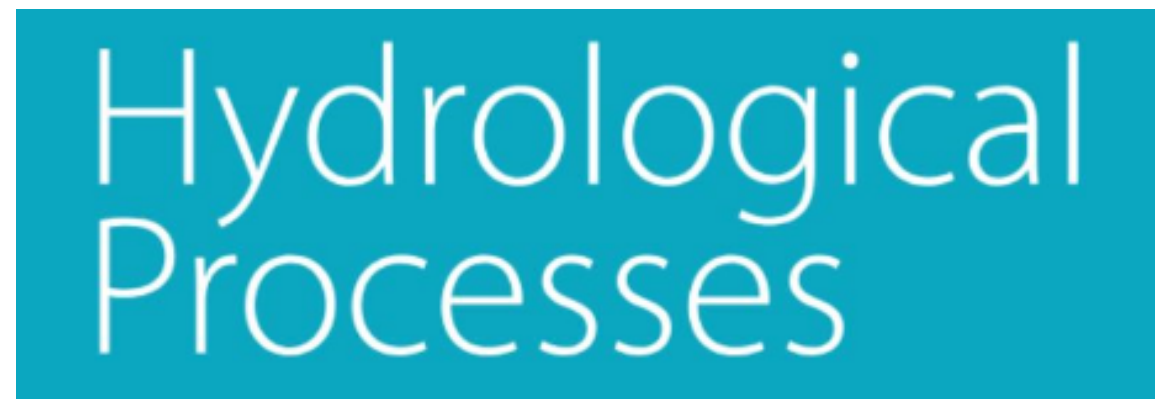

\section{INTRODUCTION}

Coastal areas host large populations of people owing to their prosperity. In the 20th century, 21 megalopolises in the coastal areas have grown rapidly to achieve a population of more than eight million, and more than a third of the global population resides within $100 \mathrm{~km}$ of the shore (Nicholls, 2008). With the increasing area affected by seawater intrusion (SWI) in coastal areas, the available amount of water resources is decreasing due to the salinization of the aquifer. Furthermore, changes caused by the salinization of coastal aquifers, such as limitations in the cultivation environment of agricultural and marine products, are damaging economic activities (Howard, 2002; Chang, 2010). 
The land-use changes due to industrial development increase surface runoff and decrease recharge of the groundwater system. Furthermore, climate change increases rainfall intensity by changing the rainfall pattern. As the number of days without rain rises, the amount of water resources discharged to the surface is increased, while the amount of recharge to the aquifer is decreased. Consequently, groundwater resources are gradually decreasing (Chamine, 2015; Bernard-Jannin et al., 2017; Azimi et al., 2018; Mondal et al., 2018; Ray and Ray, 2019). The continuous rise in sea levels accelerates the increase in the SWI range. According to the analysis method of Ghyben-Herzberg, the effect of a $1 \mathrm{~m}$ rise in the sea level on the freshwater aquifer corresponds to $40 \mathrm{~m}$ of a freshwater thickness (Todd and Mays, 2005). Sherif and Singh (1999) claimed that when the sea level rises by $0.5 \mathrm{~m}$, the effect of SWI reaches up to $9 \mathrm{~km}$ from the shore. The imbalance between the inflow and outflow from the aquifer can cause a faster drop in the freshwater groundwater level in areas with a larger pumping water quantity (Scanlon et al. 2012a). The SWI are accelerating due to the extensive use of groundwater in coastal areas, and the resulting effects by the excessive pumping of groundwater are being actively researched (Bobba, 2002; Loáiciga et al., 2012; Carretero et al., 2013; Langevin and Zygnerski, 2013; Rasmussen et al., 2013; Sefelnasr and Sherif, 2014). To efficiently establish response measures to SWI damage, one must select an area where SWI damage occurs most actively and choose response measures in line with the regional characteristics. One diagnostic method is the SWI assessment for a coastal groundwater aquifer. The general vulnerability assessment method for groundwater resources involves overlaying thematic maps linked with the scored geographic information system (GIS) data using the overlaying technique and assessing vulnerability according to the value (National Research Council, 1993). For the vulnerability assessment, the range of fixed scores is classified and presented under subjective judgment, depending on the values and types of factors associated with groundwater resources (Gogu and Dassargues, 2000; Uricchio et al., 2004). The vulnerability of groundwater resources is defined as their sensitivity to human activities and natural phenomena, and the recharge required to maintain groundwater resources and the possibility of the spread of pollutants by potential pollution sources have likewise been defined (Babiker et al., 2005). Representative vulnerability parameters for the potential pollution of groundwater resources include DRASTIC (Aller et al., 1987; Depth to groundwater, net Recharge, Aquifer media, Soil media, Topography, Impact of the vadose zone, hydraulic Conductivity), and SINTACS (Civita, 1994; depth to the groundwater table $(\mathrm{S})$, effective infiltration (I), unsaturated zone attenuation capacity $(\mathrm{N})$, soil attenuation capacity (T), hydrogeological characteristics of the aquifer (A), hydraulic conductivity (C), and topographical slope (S)). To consider the effect of coastal aquifers on SWI, GALDIT (Chachadi and Lobo-Ferreira, 2001; groundwater occurrence $(\mathrm{G})$, aquifer hydraulic conductivity (A), height of groundwater level above the sea (L), distance from the shore (D), impact of the existing status of SWI (I) and saturated thickness of the aquifer (T)) has been developed as a representative vulnerability assessment method. Recently, the assessment method of the GALDIT index has been modified for the range of the existing score and weight (Bordbar et al., 2019, 2020). The parameter replacement of GALDIT factors and the improvement of data interpolation methods have been researched as well (Klassen and Allen, 2017; Luoma et al., 2017; Hallal et al., 2019).

Several previous studies on SWI in South Korea addressed the inflow of seawater into the aquifer using the seawater monitoring network (SIMN), which was built at the national level (Lee et al., 2008). Numerous studies on SWI have been conducted on Jeju Island in South Korea (Shin and Hwang, 2020). A vulnerability assessment for SWI using GALDIT for Jeju Island was conducted for the first time in South Korea (Chang et al., 2019). Recently, studies on seawater intrusion in the inland areas of Korea have been incomplete compared with those in the island areas, but studies on the coastal areas of the west coast have begun. For example, Kim and Yang (2018) prioritized three SWI response measures for SWI-vulnerable areas when climate change was applied using the multi-criteria decision-making (MCDM) method. Chun et al. (2018) conducted a two-dimensional numerical analysis of the effects of SWI on coastal areas according to different climate change scenarios.

Studies on SWI can set different time scales according to the objectives of the study. For example, studies on the mid-to-long-term effects of SWI, such as climate change, set time scales of ten to several hundred years (Loáiciga et al., 2012; Langevin and Zygnerski, 2013; Rasmussen et al., 2013; Sefelnasar and Sherif., 2014). In contrast, studies on short repetitive variation characteristics, such as tidal effects, conduct hourly 
analyses (Kim et al., 2006; Kuan et al., 2012). In the past, techniques such as vulnerability assessments used representative values obtained through statistical tests of 10 years or longer-term data (Recinos et al., 2015; Allouche et al., 2017). To establish response measures to SWI, the flow characteristics according to the periods of salt and freshwater groundwater resources must also be considered. The assessment of flow characteristics for groundwater resources consists of factors for the spatial distribution and temporal changes in the groundwater level recorded in a time series (Gundogdu and Guney, 2007; Sun et al., 2009).

Therefore, to analyze the effect of the temporal characteristics of parameters, such as the groundwater level that changes over time, we developed a monthly SWI assessment method based on the original GLADIT. Data on SWI of coastal aquifers over the last 10 years were collected to analyze the monthly variations. The monthly vulnerability changes of the SWI were analyzed by classifying the collected data into monthly means. The GALDIT method, which is the most representative SWI assessment method, was used. We attempted to indicate spatiotemporally vulnerable areas and periods by classifying the six parameters of GALDIT into parameters that change monthly (L, I, T) and parameters that change little over time (G, A, D).

\section{DATA AND METHODS}

\subsection{Data collection for monthly GALDIT assessment.}

GALDIT is a diagnostic method based on the index and ranking that evaluates the vulnerability of coastal aquifers for six parameters considering groundwater occurrence $(\mathrm{G})$, aquifer hydraulic conductivity (A), distance from the shore (D), height of groundwater level above sea level (L), impact of the existing status of seawater intrusion (I), and saturated thickness of the aquifer (T) to examine the physical effects of coastal aquifers on the SWI. This study developed a monthly seawater intrusion vulnerability assessment method using GALDIT parameters. Data were collected from the National Groundwater Information Center (2021), the National Geographic Information Institute (2021), and the Korea Hydrographic and Oceanographic Agency (2021). The groundwater level, drill log, and groundwater survey report data were collected from the National Groundwater Information Center. Digital elevation maps (DEM) and topographic map data were collected from the National Geographic Information Institute. Tidal and other data were collected from the Korea Hydrographic and Oceanographic Agency.

For a monthly vulnerability assessment of the SWI, the parameters that were relatively static and those that changed temporally were classified as i) static parameters and ii) dynamic parameters, respectively. For the static parameter group, G, A, and D were selected. The aquifer type and A are regarded relatively static parameters in the absence of human activities. D changes when the sea level rises in the long term; however, this was excluded in this study, considering that the monthly change of the coastline due to the sea level is insignificant compared to the reference value. With regard to $\mathrm{D}$, the data observed to date were used without considering the future rises in the sea level. D that exhibited numerous fluctuations were extracted from the average distances obtained in the last 10 years.

For input data of the parameters that change with time, we employed L, I, and T. Monthly averaged values were used for the dynamic parameters. When deriving the input value of the height of the freshwater groundwater relative to the sea level, the parameter values were calculated considering that the observed groundwater level and the standard of sea level also fluctuate by month. T likewise changes monthly due to the effect of groundwater level. For each index displayed by month, we compared the parameters that were calculated by applying the effective weight using the weight and sensitivity analysis of GALDIT. Figure 1 shows a flowchart for calculating monthly GALDIT parameters.

\subsection{Modification of original GALDIT method}

GALDIT is a model employed for assessing the vulnerability of underground aquifers to seawater intrusion using six parameters related to seawater intrusion. Data about these six parameters were collected and scored according to the criteria, and maps for the parameters were generated by applying predefined weights. Scores of $2.5,5,7.5$, and 10 were determined according to the criteria. The weight of four was assigned to the index 
that had the greatest effect on seawater intrusion, and the weight varied by the effect. The relationship between the index according to the criteria and weight of the index is expressed as follows:

$\overline{\text { GALDIT }=\frac{\sum_{\mathbf{i}=1}^{6}\left(\mathbf{W}_{\mathbf{i}} \times \mathbf{R}_{\mathbf{i}}\right)}{\sum_{\mathbf{i}=1}^{6} \mathbf{W}_{\mathbf{i}}} . \quad(1)}$

Table 1 lists the ratings and weights according to the criteria for each parameter. According to the scoring method of the existing GALDIT, the highest score was 10, whereas the lowest was 2.5. The highest score of 10 was divided using the quartile method into 10, 7.5, 5 , and 2.5, according to the parameter range. In this study, the GALDIT factor variable range and the importance rating in the two columns were modified in the right column of Table 1. Thus, the highest score of 10 was divided using the decile method, and a score between 1 and 10 was assigned for the modified importance rating. The existing quartile method was used to classify aquifers according to their hydrogeological characteristics. The new distributions of scores for other parameters are listed in Table 2.

\subsection{Sensitivity analysis for GALDIT parameters}

The sensitivity analysis of GALDIT parameters was used to verify the consistency of the analysis results in the process of the vulnerability assessment (Saidi et al., 2013). To minimize the error and uncertainty of the vulnerability index, Babiker et al. (2005) and Saidi et al. (2011) adopted and evaluated appropriate parameters by performing two methods of sensitivity analysis, that is, the single parameter sensitivity analysis developed by Napolitano and Fabbri (1996) and the map removal sensitivity analysis developed by Lodwik et al. (1990). Since the development of the theoretical weights of GALDIT parameters in 2001, the modification of ranges and weights of vulnerability parameters of the GALDIT analysis method was continuously attempted (Kazakis et al., 2018; Gorgij and Moghaddam, 2016). Among these attempts, the sensitivity analysis of the parameters helps determine the weights effectively by comparing with theoretical weights in assessing the vulnerability with the score and weight of each index (Gontara et al., 2016; Mahrez et al., 2018). The existing GALDIT has determined parameters using averages for a long time. When calculating the monthly SWI vulnerability index, the error and uncertainty of the weights of the parameters must be minimized.

The single-parameter sensitivity analysis compares the "effective" or "real" weight with the theoretical weight for the area in which the index is assessed. The effective weight W (\%) for the assessment area of the GIS is calculated as follows (Babiker et al., 2005):

$$
\overline{\mathbf{W}=\frac{\mathbf{P}_{\mathbf{r}} \mathbf{P}_{\mathbf{w}}}{\mathbf{V}} \times \mathbf{1 0 0}, \quad(2)}
$$

where $\mathrm{W}$ denotes the effective weight for each index, $\mathrm{P}_{\mathrm{r}}$ and $\mathrm{P}_{\mathrm{w}}$ denote the rating and weighting values for each index, respectively, and $\mathrm{V}$ denotes the total vulnerability index. In this study, the weight of the original GALDIT was compared with the effective weight by assessing the monthly GALDIT.

\subsection{STUDY AREA}

Korea has long coastlines and various coastal terrains, as it is surrounded by the sea on three sides. According to recent data, the lengths of the coastline for the western, southern, and eastern coasts of South Korea span approximately 4,900,3,300, and $600 \mathrm{~km}$, respectively (Ministry of Oceans and Fisheries, 2003). The west coast has numerous bays, peninsulas, capes, and islands due to the crooked and broken coastline. In particular, a ria coast is developing in the coastal areas of the Dadohae and Taean Peninsula, where the coastlines are extremely crooked. Furthermore, this is also a place where numerous soils of terrestrial origin are transported and deposited owing to the gentle the terrain slope, severe tidal differences, and the flow through of Korea's great rivers. Consequently, large tidal flats develop along the west coast, and low hilly mountains or large and small coastal plains are distributed inland. 
Among the sea areas under the influence of seawater intrusion in South Korea, this study targeted the western coast with severe tidal differences, where the coastline is long, and the terrain slope is gentle. The selected study area was a coastal area of the inland, excluding islands in the north, where urban areas are concentrated on the western coast of South Korea. The study area consists of nine administrative districts: Incheon, Asan, Ansan, Gimpo, Hwaseong, Siheung, Pyeongtaek, Dangjin, and Osan. In all of these nine areas, the manufacturing industry is developing and urbanization is accelerating, and there is a continuous influx of population. Incheon is the third-largest city in terms of population in South Korea after Seoul and Busan, and has a developed logistics industry as it hosts the Incheon International Airport and Incheon Port. Ansan is a planned industrial city, where a population of a similar size to the residential one flows during the day due to numerous manufacturing plants. The manufacturing industry was also developed in Gimpo, Hwaseong, Siheung, Pyeongtaek, Dangjin, and Osan. There is Sihwa Lake Seawall in Siheung, Hwaseong, and Ansan, where industrial clusters and tourist attractions were developed. Daebu Island, the only island in the study area, was included in the study area because it is connected to a freshwater lake through the Sihwa Lake Seawall. The total area of the study is $3976.59 \mathrm{~km}^{2}$, and the length of the coastline is $608.1 \mathrm{~km}$. The automatic monitoring data and drill logs of the National Groundwater Information Center were used to assess the seawater intrusion vulnerability of the study area. There were 58 groundwater level stations in total. Further, seawater levels were observed at nine seawater level stations. Figure 2 shows the locations of the study area, rivers, coastlines, groundwater level stations, and sea water level stations.

\section{RESULTS}

\subsection{Static GALDIT parameters}

In this section, we examine the analysis results for parameters with slight changes over time, i.e., groundwater occurrence $(\mathrm{G})$, aquifer hydraulic conductivity $(\mathrm{A})$, and distance from the shore (D). The histogram colors in Figure 3 represent the ratings divided by the decile method, and the values were divided into 11 levels by adding 7.5 of the unconfined included in $\mathrm{G}$. The y-axis represents the cumulative ratio of the area according to the rating, the secondary $y$-axis represents the score of the index, and the values indicated by the broken line represent the total average of the study area.

G or aquifer types are classified into confined aquifers, unconfined aquifers, leaky aquifers, and bounded aquifers. The most vulnerable aquifer type is the confined aquifer. The scores of groundwater occurrence were divided into four levels in the same way as the existing scoring method, and the theoretical weight was one. This study assessed the alluvial layer in a free-surface aquifer of a shallow area. The aquifer type in all areas was an unconfined aquifer, and the G score was 7.5. Figure 4 (a) shows the G index.

Higher A induces smoother groundwater flow and exhibits larger vulnerability to the SWI. The theoretical weight was three in this case. When the aquifer hydraulic conductivity exceeds $40 \mathrm{~m} /$ day, it is the most vulnerable, and it is attributed to a score of ten. When the aquifer hydraulic conductivity was less than 4 $\mathrm{m} /$ day, a score of one was given. Examination of the area ratios of each score yields A below $4 \mathrm{~m} /$ day at the largest ratio of $94.23 \%$. Some areas have a high aquifer hydraulic conductivity near Pyeongtaek. The total average score of the study area was determined as 1.07. Figure 4 (b) shows the distribution of A.

$\mathrm{D}$ was determined based on the observed coastline. Areas below $500 \mathrm{~m}$ away from the shore are most vulnerable to SWI, and areas more than $1,300 \mathrm{~m}$ away from the coast are given a score of one. The theoretical weight, an index that can intuitively show vulnerability, was four. Most parts of the study area, accounting for $84.14 \%$, were $1,300 \mathrm{~m}$ from the shore. Areas $1,000 \mathrm{~m}$ or less away from the shore with a score of less than five accounted for $10.88 \%$, and areas less than $500 \mathrm{~m}$ away from the shore accounted for $2.46 \%$. The average score for the study area was 1.86 . Figure 3 shows the percentages and average scores of static GALDIT parameters. Figure 4 (c) shows the distribution of the D index.

\subsection{Dynamic GALDIT parameters}

3.2.1 Height of groundwater level above sea level (L)

In this section, we examine the analysis results of monthly averages for the data from 2010 to 2019 regarding 
the parameters that change significantly over time, that is, the height of the groundwater level above sea level (L), the impact of the existing status of seawater intrusion (I), and saturated thickness of the aquifer $(\mathrm{T})$.

$\mathrm{L}$ was most vulnerable to SWI when it was less than $1 \mathrm{~m}$, and the score was ten in this case. When $\mathrm{L}$ exceeds $2.6 \mathrm{~m}$, the score is the lowest at one, and the theoretical weight is four. This index changes monthly. The existing calculation method is used to observe $\mathrm{L}$ and compare the range values. In this study, the score was determined by comparing the measured groundwater level from the sea level, with the monthly sea level height measured at the sea water level station. The sea level observation data of the sea water level station were interpolated by setting the coastline as the domain. L was determined by the minimum distance to the interpolated coastline. The histogram in Figure 6 shows the distribution of scores represented by the decile method. The $\mathrm{y}$-axis on the left is the cumulative ratio of data $\mathrm{L}$ according to the rating, and the secondary $\mathrm{y}$-axis represents the average of the data expressed in a straight line. As a consequence of calculating the monthly groundwater height relative to sea level, April exhibited the highest average of the study area at 1.25, and August had the lowest average at 1.21. Owing to the nature of Korea's climate, the groundwater level of the unconfined aquifer rises during the rainy season or intensive rainfall from June to August. The sea level also rose the most in August; however, the extent of increase in the sea level was smaller than that of the groundwater level, and it was the lowest. The variations in groundwater level differed depending on the area, albeit the sea level was the lowest in January and February. In April, when the rainfall is small, and the use of groundwater is concentrated, the groundwater level drops significantly, making it a period that is most vulnerable to SWI.

\subsubsection{Impact of the existing status of seawater intrusion (I)}

For the current SWI situation, we used electrical conductivity, which is easily obtained from National groundwater monitoring network in KOREA. Existing studies used the molar ratio of $\mathrm{Cl}^{-}$; however, observations were irregular, and the requirement for the length of continuous data could not be satisfied. Chang et al. (2019) used the electrical conductivity data obtained from the seawater intrusion monitoring network as input data for the I parameter in the GALDIT assessment. The present study also used electrical conductivity data obtained from the National Groundwater Monitoring Network, whose quality control for observation data is excellent. Based on the rating of Chang et al. (2019), it was most vulnerable when the electrical conductivity exceeded $3,000 \mu \mathrm{s} / \mathrm{m}$, and a score of two was attributed if it was below $200 \mu \mathrm{s} / \mathrm{m}$. This index can indicate monthly changes, and the theoretical weight of the current SWI situation is one. The colors in the histogram in Figure 9 express the rating divided by the decile method. The y-axis on the left is the cumulative ratio of data I according to the rating, and the secondary y-axis on the right represents the average of the data expressed by a straight line. When the thematic map in Figure 7 is examined with the naked eye, one observes that the change in parameter values is not large in most areas. However, the area in the north of the study area shows higher values in March, which remained high until April and dropped from May. The values increased again in September, slightly decreased in October, and were maintained at 3-4 in November. The straight line in the graph in Figure 8 represents the average parameter value for each month. Upon comparison of the monthly average parameters, the most vulnerable month is September, with the average of all areas at 3.65, whereas the least vulnerable month was February, with the average at 3.32.

\subsubsection{Saturated thickness of the aquifer $(\mathrm{T})$}

$\mathrm{T}$ was determined using drill logs (www.gims.go.kr). The bottom point of the unconfined aquifer was estimated by analyzing the sample and stratum composition from the drill logs. $T$ was calculated from the height of the groundwater level observed in real-time. High-quality data over a continuous period of 10 years were used among the groundwater level data observed in real-time. The saturated thickness of the aquifer is most vulnerable to SWI when it exceeds $10 \mathrm{~m}$, and it is satisfactory when it is less than $2 \mathrm{~m}$, and the score is one. The theoretical weight of $\mathrm{T}$ was two.

The colors in the histogram in Figure 10 express the ratings divided by the decile method. The y-axis represents the cumulative ratio of the area according to the rating, the secondary $y$-axis represents the 
scores of the index, and the values indicated by the broken line indicate the total average of the study area. The analysis reveals the minimum score at four, which indicates all $\mathrm{T}$ were above $4 \mathrm{~m}$. August was the most vulnerable month at 9.12, and April had the lowest score of 8.92. T is an index related to the real-time groundwater level. It is believed that $\mathrm{T}$ increases in July and August when significant recharge occurs due to rainfall, and it decreases from February to April when there are fewer rainfall events, and the pumping of groundwater increases.

\subsection{SWI assessment of study-site based on monthly GALDIT index}

For the monthly GALDIT index to which the theoretical weight was applied, the average of observations for 10 years was applied for $\mathrm{G}, \mathrm{A}$, and $\mathrm{D}$, whereas the parameters that changed monthly were applied for L, I, and T. The colors of the histogram in Figure 11 express the range of the calculated GALDIT index. The yaxis represents the cumulative ratio of the area according to the index range, the secondary y-axis represents the GALDIT index, and the value indicated by the broken line represents the average GALDIT index of the entire study area. The score range that occupied the highest proportion was $2-3$, which accounted for $78 \%$ in February, 78 \% in May, and $78 \%$ in July. The calculation results show that the most vulnerable month was September, when the average GALDIT index of the study area was 3.03. The ratio of areas with scores [?] 5 was highest in September (8.87\%), followed by October (8.64 \%), and April (8.63\%). In September, $\mathrm{L}$ was relatively robust at 1.19 , as the third place from the bottom. However, it was the most vulnerable month in terms of I and the third from the top in terms of $\mathrm{T}$. Thus, it was the most vulnerable month when the theoretical weight was applied. Figure 12 (a) shows the calculation result of the original GALDIT using the quartile method, and Figure 12 (b) shows the result of September, which is the most vulnerable month in the monthly GALDIT results using the decile method. In Figure 12 (a), the vulnerable areas are the coastal area in the south of Incheon and the areas near Incheon and Siheung, where the index value is approximately 8-9. Upon comparison of the monthly GALDIT map for September in Figure 12 (b) with the original, the index of the Gimpo area indicated in orange in the northeastern side of the study area is 5-6 in most periods, exhibiting moderate vulnerability. The western coast area of Gimpo, which does not appear in the original GALDIT, shows an index value of 7-8, indicating the boundary between moderate and high vulnerability. The SWI vulnerable area on the southern coast of Incheon has an index value is 6-7 at both edges around the area protruding to the coast, showing a different pattern from the original GALDIT map. In the Pyeongtaek area, the eastern inland area exhibited low vulnerability. However, in the monthly GALDIT map, the yellow parts showed index values of 3-5, revealing differences in the seawater intrusion vulnerability. Most of the areas excluding the coast showed little differences in the degree; however, in the monthly GALDIT map, they showed partial differences, indicating low vulnerability. In the entire study area, the inland areas up to $1 \mathrm{~km}$ away from the coastline are considered areas of moderate to high vulnerability.

\subsection{Single parameter sensitivity analysis for Monthly GALDIT index using effective weight}

The effective weight was calculated for sensitivity analysis, as summarized in Table 3. According to Babiker et al. (2005), the weight used for vulnerability assessment can vary according to the study area. The 'effective weight' represents the weight that is actually applied to assess the vulnerability index. As a result of the sensitivity analysis, the index with the largest effective weight was T. Note that an average value of 8 to 9 was assigned to the parameter value of $\mathrm{T}$ in the process of applying the modified GALDIT method for hydrogeological data in the previous section. The ratio of the effective weight of $\mathrm{T}$ was high, owing to the parameter value that was calculated to be higher than the other parameter values. Although the theoretical weight was high for $\mathrm{L}$ and $\mathrm{D}$, due to the low parameter scores in most of the study area, the ratio of the score of the GALDIT index decreased, resulting in a low ratio of effective weight. The highest values of the effective index for $\mathrm{L}$ and $\mathrm{D}$ were 59.82 and $59.19 \%$, respectively, whereas their average values were significantly lower, at 10.53 and $14.88 \%$, respectively.

\section{CONCLUSION}

An accurate diagnosis of SWI vulnerability is required for the sustainable utilization of groundwater re- 
sources in coastal areas. GALDIT is a SWI vulnerability assessment method that shows representative values using a statistical test of observed data. This study differentiated the analysis method by classifying the six parameters of the existing GALDIT into static and dynamic parameters. For the static parametersG (groundwater occurrence), A (aquifer hydraulic conductivity), and D (distance from the shore) - similar to the existing method, the annual average or average of the observed values was used. For the dynamic parameters - L (height to groundwater level above sea level), I (impact of existing status of seawater intrusion), and $\mathrm{T}$ (thickness of the aquifer) - monthly averages were used to reflect the observed values that change every month. In the existing score range, the most vulnerable and least vulnerable values were divided by quartiles for the assessment of SWI vulnerability. The existing quartile methods cannot respond sensitively to relatively small changes in SWI vulnerability because the criteria for dividing scores are wide. The present study divided the values assigned to each parameter by the decile method to sensitively reflect the degree of vulnerability that changes every month in areas where the seasonal variation of the dynamic index is evident, as in South Korea.

As a result of calculating the GALDIT index by applying the existing weight, September was selected as the most vulnerable month at a value of 3.03. In September, the ratio of areas with a score of five or higher was the highest at $8.87 \%$, and it was the most vulnerable month for I and the third most vulnerable month for T. Thus, September was the month most vulnerable to the final GALDIT parameters. In the range of the existing GALDIT index, 3.03 is a value that indicates no vulnerability. Consequently, the vulnerability was low because it also increased a large part of the inland area that was not affected by the impact of the existing status of seawater intrusion.

In the monthly seawater intrusion assessment, the effective weight of $\mathrm{T}$ was calculated to be high. Because of the nature in South Korea, the saturated thickness of the aquifer is somewhat high, and most areas are highly vulnerable. Because of $\mathrm{T}$, which is mostly thick, it is difficult to indicate the differences in vulnerability even if time variability is considered. L was determined based on the sea level observed by sea water level stations near the groundwater level measuring site, instead of the existing method of indicating the groundwater level based on the sea level.

The sensitivity analysis results showed that $\mathrm{T}$ was the most important index, as the $\mathrm{T}$ score was calculated to be higher than the other parameters, indicating that it is the most sensitive index. Thus, the calculated effective weight was likewise high. When performing the monthly GALDIT assessment in the future, the modification of rating criteria and weight of each parameter will likewise be necessary. We attempted to modify the existing GALDIT assessment method within a range that does not exceed the criteria, but with differences in the parameters that act sensitively depending on the characteristics of the study area. The sensitive parameters can have a significant effect on the SWI or may be overestimated in some cases.

To the best of our knowledge, this study attempted the first monthly analysis of the GALDIT parameters based on the decile method. If intensive response measures are applied to vulnerable areas using the methodology of this study and operational plans are established considering the vulnerable period, the SWI damage could be effectively reduced, and sustainable utilization of groundwater in the coastal areas could be realized.

It may be necessary to improve the theoretical weight and expand the variable range considering static and dynamic parameters representing extreme situations due to climate change in the future. Furthermore, a follow-up study is required to improve the equations for calculating GALDIT parameters according to site characteristics.

\section{ACKNOWLEDGEMENTS}

This research was supported by a grant from the Development Program of Minimizing of Climate Change Impact Technology funded through the National Research Foundation of Korea (NRF) of the Korean government (Ministry of Science and ICT, Grant No. NRF-2020M3H5A1080735).

\section{References}


Abarca, E., Vázquez-Suñé, E., Carrera, J., Capino, B., Gámez, D. \& Batlle, F. (2006). Optimal design of measures to correct seawater intrusion. Water Resource Research, 42. http://dx.doi.org/10.1029/2005WR004524.

Aller, L., Bennett, T., Lehr, J.H., Petty, R.J., \& Hackett, G. (1987). DRASTIC: A Standardized System for Evaluating Groundwater Pollution Potential Using Hydrogeologic Settings. Environmental Protection Agency NWWA/EPA Series EPA-600/2-87-035. Dublin, Ireland: National Water Well Association.

Allouche, N., Maanan, M., Gontara, M., Rollo, N. \& Jmal, I. (2017) A global risk approach to assessing groundwater vulnerability. Environmental Modelling and Software, Elsevier, 88, pp. 168-182. ¡hal-01512478i

Anghileri, D., Pianosi, F. \& Soncini-Sessa, R. (2014) Trend detection in seasonal data: From hydrology to water resources. Journal of Hydrology, -. 10.1016/j.jhydrol.2014.01.022.

Azimi, S., Moghaddam, M.A. \& Monfared, S.A.H. (2018). Spatial assessment of the potential of groundwater quality using fuzzy AHP in GIS. Arabian Journal of Geosciences, 11(7), p. 142.

Babiker, I. S., Mohamed, M. A., Hiyama, T., \& Kato, K. (2005). A GIS-based DRASTIC model for assessing aquifer vulnerability in Kakamigahara Heights, Gifu Prefecture, Central Japan. Science of the Total Environment, 345, pp. 127-140.

Bernard-Jannin, L., Sun, X., Teissier, S., Sauvage, S., \& Sanchez-Perez, J.M. (2017). Spatiotemporal analysis of factors controlling nitrate dynamics and potential denitrification hot spots and hot moments in groundwater of an alluvial floodplain. Ecological Engineering, 103, pp. 372-384.

Bobba, A.G. (2002). Numerical modelling of salt-water intrusion due to human activities and sea-level change in the Godavari Delta, India. Hydrological Science Journal, 47, S67-S80.

Bordbar, M., Neshat, A., \& Javadi, S. (2019) Modification of the GALDIT framework using statistical and entropy models to assess coastal aquifer vulnerability. Hydrological Sciences Journal, 64(9), pp. 1117-1128. 10.1080/02626667.2019.1620951

Bordbar, M., Neshat, A., Javadi, S., Pradhan, B., \& Aghamohammadi, H. (2020). Meta-heuristic algorithms in optimizing GALDIT framework: A comparative study for coastal aquifer vulnerability assessment. Journal of Hydrology, 585, p. 124768. 10.1016/j.jhydrol.2020.124768.

Botero-Acosta, A. \& Donado, L.D. (2015). Laboratory scale simulation of hydraulic barriers to seawater intrusion in confined coastal aquifers considering the effects of stratification. Process and Environment Science, 25, pp. 36-43.

Carretero, S., Rapaglia, J., Bokuniewicz, H., \& Kruse, E. (2013). Impact of sea-level rise on saltwater intrusion length into the coastal aquifer, Partido de La Costa, Argentina. Continental Shelf Research, 61-62, pp. $62-70$.

Chachadi, G. \& Lobo-Ferreira, J.P., (2001). Sea water intrusion vulnerability mapping of aquifers using the GALDIT method. COASTIN Newsletter, 4, 7-9p.

Chamine, H.I. (2015). Water Resources Meet Sustainability: New Trends in Environmental Hydrogeology and Groundwater Engineering. Environmental Earth Sciences, 73, pp. 2513-2520. 10.1007/s12665-014$3986-\mathrm{y}$.

Chang, N.-B. (2010). Effects of urbanization on groundwater: An engineering case-based approach for sustainable development. 10.1061/9780784410783.

Chang, S.W., Chung, I.-M., Kim, M.-G., Tolera, M. \& Koh, G.-W. (2019) Application of GALDIT in Assessing the Seawater Intrusion Vulnerability of Jeju Island, South Korea. Water, 11, p. 1824. 10.3390/w11091824

Chun, J.A., Lim, C., Kim, D. \& Kim, J.S. (2018) Assessing Impacts of Climate Change and Sea-Level Rise on Seawater Intrusion in a Coastal Aquifer. Water, 10, p. 357. 10.3390/w10040357 
Civita, M. (1994) Le Carte della vulnerabilita degli acquiferi all'inquinamento: teoria\&pratica [Aquifer vulnerability to pollution maps: theory and practice]. Pitagora, Bologna, Italy.

Gogu, R.C. \& Dassargues, A. (2000), Current trends and future challenges in groundwater vulnerability assessment using overlay and index methods. Environmental Geology, 39(6), pp. 549-559.

Gontara, M., Allouche, N., Jmal, I. \& Bouri, S. (2016) Sensitivity analysis for the GALDIT method based on the assessment of vulnerability to pollution in the northern Sfax coastal aquifer, Tunisia. Arabian Journal of Geosciences, 9, 10.1007/s12517-016-2437-3.

Gorgij, A.D. \& Moghaddam, A.A. (2016). Vulnerability Assessment of saltwater intrusion using simplified GAPDIT method: a case study of Azarshahr Plain Aquifer, East Azerbaijan, Iran. Arabian Journal of Geosciences, 9. 10.1007/s12517-015-2200-1.

Gundogdu, K.S., \& Guney, I. (2007). Spatial analyses of groundwater levels using universal kriging. Journal of Earth System Science, 116(1), pp. 49-55.

Hallal, D., Khelfi, M.E.A., Zahouani, S., Benamghar, A., Haddad, O., Ammari, A., \& Lobo-Ferreira, J. (2019). Application of the GALDIT method combined with geostatistics at the Bouteldja aquifer (Algeria). Environmental Earth Sciences, 78. 10.1007/s12665-018-8005-2.

Howard, K. (2002). Urban Groundwater Issues-An Introduction. 8. 10.1007/978-94-010-0409-1_1.

Jang, S., Hamm, SY., Yoon, H., Kim, G.-B., Park, J.-H. \& Kim, M.S. (2015) Predicting long-term change of groundwater level with regional climate model in South Korea. Geosciences Journal, 19, pp. 503-513. 10.1007/s12303-015-0002-9

Kazakis, N., Spiliotis, M., Pliakas, F.-K., \& Papadopoulos, B. (2017) A fuzzy multicriteria categorization of the GALDIT method to assess seawater intrusion vulnerability of coastal aquifers. Science of the Total Environment, 621. 10.1016/j.scitotenv.2017.11.235.

Kim, I.-H. \& Yang, J.-S. (2018) Prioritizing countermeasures for reducing seawater-intrusion area by considering regional characteristics using SEAWAT and a multi-criteria decision-making method. Hydrological Processes, 32. 10.1002/hyp.13283.

Kim, K.-Y., Seong, H. J., Kim, T. H., Park, K.-H., Woo, N., Park, Y.-S., Koh, G.-W.\& Park, W.B. (2006). Tidal effects on variations of fresh-saltwater interface and groundwater flow in a multilayered coastal aquifer on a volcanic island (Jeju Island, Korea). Journal of Hydrology, 330, pp. 525-542. 10.1016/j.jhydrol.2006.04.022.

Klassen, J. \& Allen, Diana. (2017). Assessing the Risk of Saltwater Intrusion in Coastal Aquifers. Journal of Hydrology, 551, 10.1016/j.jhydrol.2017.02.044.

Korea Hydrographic and Oceanographic Agency. http://www.khoa.go.kr (accessed on 22 Feburary 2021)

Kuan, W. K., Jin, G., Xin, P., Robinson, C., Gibbes, B., \& Li, L. (2012) Tidal influence on seawater intrusion in unconfined coastal aquifers. Water Resources Research, 48, W02502, 10.1029/2011WR010678.

Langevin, C.D. \& Zygnerski, M. (2013). Effect of sea-level rise on salt water intrusion near a coastal well field in Southeastern Florida. Groundwater, 51, pp. 781-803.

Lee, J.-Y., Yi, M.-J., Song, S.-H., \& Lee, G.-S. (2008) Evaluation of seawater intrusion on the groundwater data obtained from the monitoring network in Korea. Water International, 33(1), pp. 127-146. $10.1080 / 02508060801927705$

Loaiciga, H.A., Pingel, T.J., \& Garcia, E.S. (2012) Seawater intrusion by sea-level rise: scenarios for the 21st century. Groundwater, 50, pp. 37-47. 
Lodwick, W., Monson, W., \& Svoboda, L. (1990). Attribute error and sensitivity analysis of map operations in geographical information systems. International Journal of Geographical Information Science, 4, pp. 413-428. 10.1080/02693799008941556.

Luoma, J., Ruutu, S., King, A.W., \& Tikkanen, H. (2017) Time delays, competitive interdependence, and firm performance. Strategic Management Journal, 38, pp. 506-525. https://doi.org/10.1002/smj.2512

Luyun, R., Momii, K., \&Nakagawa, K. (2011). Effects of recharge wells and flow barriers on seawater intrusion. Ground Water, 49, pp. 239-249.

Mahrez, B., Klebingat, S., Houha, B, \& Houria, K. (2018). GIS-based GALDIT method for vulnerability assessment to seawater intrusion of the Quaternary coastal Collo aquifer (NE-Algeria). Arabian Journal of Geosciences, 11. 10.1007/s12517-018-3400-2.

Ministry of Oceans and Fisheries. (2003). Coast condition survey report-West coast, Ministry of Oceans and Fisheries.

Mondal, I., Bandyopadhyay, J., \& Chowdhury, P. (2019). A GIS based DRASTIC model for assessing groundwater vulnerability in Jangalmahal area, West Bengal, India. Sustainable Water Resources Management, 5, pp. $557-573$.

Napolitano, P. \& Fabbri, A.G. (1996) Single Parameter Sensitivity Analysis for Aquifer Vulnerability Assessment Using DRASTIC and SINTACS. In: Kovar, K. and Nachtnebel, H.P., Eds., HydrolGis Application of Geographic Information Systems in Hydrology and Water Resources Management, IAHS Publication, Wallingford, pp. 559-566.

National Geographic Information Institute. http://www.ngii.go.kr ((accessed on 22 Feburary 2021)

National Groundwater Information Center. http://www.gims.go.kr (accessed on 22 Feburary 2021)

National Research Council, (1993). Ground water vulnerability assessment: Predicting relative contamination potential under conditions of uncertainty, National Academy Press, Washington, DC, pp. 42-63.

Nicholls, R. J., Nicholls, P.P.W., Burkett, V., Colin D.W., \& Hay, J. (2008). Climate Change and Coastal Vulnerability Assessment: Scenarios for Integrated Assessment. Sustainability Science, 3, pp. 89-102. 10.1007/s11625-008-0050-4

Pool, M. \& Carrera, J. (2010). Dynamics of negative hydraulic barriers to prevent seawater intrusion. Hydrogeology Journal, 18, pp. 95-105.

Rasmussen, P., Sonnenborg, T.O., Goncear, G. \& Hinsby, K. (2013). Assessing impacts of climate change, sea level rise, and drainage canals on saltwater intrusion to coastal aquifer. Hydrology and Earth System Sciences, 17, pp. 421-443.

Rasmussen, P., Sonnenborg, T.O., Goncear, G., \& Hinsby, K. (2013) Assessing impacts of climate change, sea level rise, and drainage canals on saltwater intrusion to coastal aquifer. Hydrology and Earth System Science, 17, pp. 421-443.

Ray, S.S. \& Ray, A., (2019). Major ground water development issues in South Asia: an overview. In: Ground Water Development-Issues and Sustainable Solutions. Springer, Singapore, pp. 3-11.

Recinos, N., Kallioras, A., Pliakas, F.-K. \& Schuth, C. (2014). Application of GALDIT index to assess the intrinsic vulnerability to seawater intrusion of coastal granular aquifers. Environmental Earth Sciences, 73. 10.1007/s12665-014-3452-x.

Saidi, S., Bouri S., \& Dhia, H.B. (2011) Sensitivity analysis in groundwater vulnerability assessment based on GIS in the Mahdia-Ksour Essaf aquifer, Tunisia: a validation study. Hydrological Sciences Journal, 56(2), pp. 288-304. 10.1080/02626667.2011.552886 
Saidi, S., Bouri, S., \& Dhia, H.B. (2013). Groundwater management based on GIS techniques, chemical indicators and vulnerability to seawater intrusion modelling: application to the Mahdia-Ksour Essaf aquifer, Tunisia. Environmental Earth Sciences, 70, pp. 1551-1568. 10.1007/s12665-013-2241-2

Sefelnasr, A. \& Sherif, M. (2014) Impacts of seawater rise on seawater intrusion in the Nile Delta aquifer. Egypt. Groundwater, 52, pp. 264-276.

Sherif, M.M. \& Singh, V.P. (1999). Effect of climate change on seawater intrusion in coastal aquifers. Hydrological Processes, 13, pp. 1277-1287.

Shin, J. \& Hwang, S. (2020) A Borehole-Based Approach for Seawater Intrusion in Heterogeneous Coastal Aquifers, Eastern Part of Jeju Island, Korea. Water, 12, p. 609. 10.3390/w12020609

Sriapai, T., Walsri, C., Phueakphum, D. \& Fuenkajorn, K. (2012). Physical model simulations of seawater intrusion in unconfined aquifer. Songklanakarin Journal of Science and Technology, 34, pp. 679-687.

Sun, Y., Kang, S., Li, F., \& Zhang, L. (2009) Comparison of interpolation methods for depth to groundwater and its temporal and spatial variations in the Minqin oasis of northwest China. Environmental Modelling \& Software, 24(10), pp. 1163-1170.

Todd, D. K. \& Mays L. W. (2005). Groundwater Hydrology (3rd edition). John Wiley \& Sons, Inc., New York, USA.

Uricchio, V.F., Giordano, R., \& Lopez, N. (2004). A fuzzy knowledge-based decision support system for groundwater pollution risk evaluation. Journal of Environmental Management, 73(3), pp. 189-197.

Figure legends

Figure 1. Procedure of monthly-based GALDIT index assessment

Figure 2. Study area in western coastal area of South Korea.

Figure 3. Distribution of static parameters' rating for groundwater occurrence $(\mathrm{G})$, aquifer hydraulic conductivity (A), and distance from the shore (D)

Figure 4. Thematic maps of static parameters' rating for groundwater occurrence (G), aquifer hydraulic conductivity (A) and distance from the shore (D)

Figure 5. Thematic maps of the dynamic parameter's rating for monthly height of groundwater level above sea level (L)

Figure 6. Distribution of the dynamic parameter's rating for monthly height of groundwater level above sea level (L)

Figure 7. Thematic maps of the dynamic parameter's rating for monthly impact of existing status of seawater intrusion (I)

Figure 8. Distribution of the dynamic parameter's rating for monthly impact of existing status of seawater intrusion (I)

Figure 9. Thematic maps of the dynamic parameter's rating for monthly saturated thickness of aquifer $(\mathrm{T})$

Figure 10. Distribution of the dynamic parameter's rating for saturated thickness of aquifer $(\mathrm{T})$

Figure 11. Distribution of monthly GALDIT index

Figure 12. A comparison between Original GALDIT yearly average and monthly GALDIT in September

Table 1 . Theorical weights and rates for GALDIT 


\begin{tabular}{llll}
\hline Parameter & Weight & $\begin{array}{l}\text { GALDIT Factor } \\
\text { Variable Range }\end{array}$ & Importance Rating \\
\hline Groundwater occurrence & 1 & $\begin{array}{l}\text { Confined aquifer } \\
\text { Unconfined aquifer Leaky } \\
\text { confined aquifer Bounded } \\
\text { aquifer }\end{array}$ & 107.552 .5 \\
& $>4010-405-10<5$ & 107.552 .5 \\
$\begin{array}{l}\text { Aquifer hydraulic } \\
\text { conductivity (m/day) }\end{array}$ & 3 & $<1.01 .0-1.51 .5-2.0>2.0$ & 107.552 .5 \\
$\begin{array}{l}\text { Height of groundwater } \\
\text { level above sea level }(\mathrm{m})\end{array}$ & 4 & $<500500-700750-1000$ & 107.552 .5 \\
$\begin{array}{l}\text { Distance from the shore } \\
\text { (m) }\end{array}$ & 4 & $>1000$ & 107.552 .5 \\
$\begin{array}{l}\text { Impact of existing status } \\
\text { of seawater intrusion } \\
(\mu \mathrm{s} / \mathrm{m})\end{array}$ & 1 & $>30002000-3000$ & 107.552 .5 \\
$\begin{array}{l}\text { Saturated thickness of } \\
\text { the aquifer }(\mathrm{m})\end{array}$ & 2 & $>1000-2000<1000$ & \\
\hline
\end{tabular}

Table 2. Modified rates for GALDIT

\begin{tabular}{|c|c|c|}
\hline Parameter & Modified Variable Range & Modified Importance Rating \\
\hline Groundwater occurrence & $\begin{array}{l}\text { Confined aquifer Unconfined } \\
\text { aquifer Leaky confined aquifer } \\
\text { Bounded aquifer }\end{array}$ & 107.552 .5 \\
\hline $\begin{array}{l}\text { Aquifer hydraulic conductivity } \\
\text { (m/day) }\end{array}$ & $\begin{array}{l}>40 \quad 34-40 \quad 28-34 \quad 22-28 \quad 16-22 \\
10-16 \quad 8-10 \quad 6-8 \quad 4-6<4\end{array}$ & 10987654321 \\
\hline $\begin{array}{l}\text { Height of groundwater level } \\
\text { above sea level }(\mathrm{m})\end{array}$ & $\begin{array}{l}<1.0 \quad 1.0-1.2 \quad 1.2-1.4 \quad 1.4-1.6 \\
1.6-1.8 \quad 1.8-2.0 \quad 2.0-2.2 \quad 2.2-2.4 \\
2.4-2.6>2.6\end{array}$ & 10987654321 \\
\hline Distance from the shore $(\mathrm{m})$ & $\begin{array}{l}<500 \quad 500-600600-700700-800 \\
800-900900-10001000-1100 \\
1100-12001200-1300>1300\end{array}$ & 10987654321 \\
\hline $\begin{array}{l}\text { Impact of existing status of } \\
\text { seawater intrusion }(\mu \mathrm{s} / \mathrm{m})\end{array}$ & $\begin{array}{l}>30002600-30002200-2600 \\
1800-22001400-18001000-1400 \\
600-1000200-600<200-\end{array}$ & 10987654321 \\
\hline $\begin{array}{l}\text { Saturated thickness of the } \\
\text { aquifer }(\mathrm{m})\end{array}$ & $\begin{array}{l}>10 \quad 9-10 \quad 8-9 \quad 7-8 \quad 6-7 \quad 5-6 \quad 4-5 \quad 3-4 \\
2-3<2\end{array}$ & 10987654321 \\
\hline
\end{tabular}

Table 3. A comparison between theoretical weight and effective weight

\begin{tabular}{lllllll}
\hline Parameter & Theoretical weight & Theoretical weight (\%) & RANK & Effective weight (\%) & Effective weight (\%) & Effective \\
\hline & & & & $\min$ & $\max$ & mean \\
G & 1 & 6.67 & 5 & 6.44 & 26.11 & 17.63 \\
A & 3 & 20 & 3 & 2.56 & 45.44 & 7.45 \\
L & 4 & 26.67 & 1 & 4.82 & 59.82 & 10.53 \\
D & 4 & 26.67 & 1 & 4.97 & 59.19 & 14.88 \\
I & 1 & 6.67 & 5 & 3.42 & 21.62 & 7.87 \\
T & 2 & 13.33 & 4 & 9.44 & 49.29 & 41.50 \\
\hline
\end{tabular}




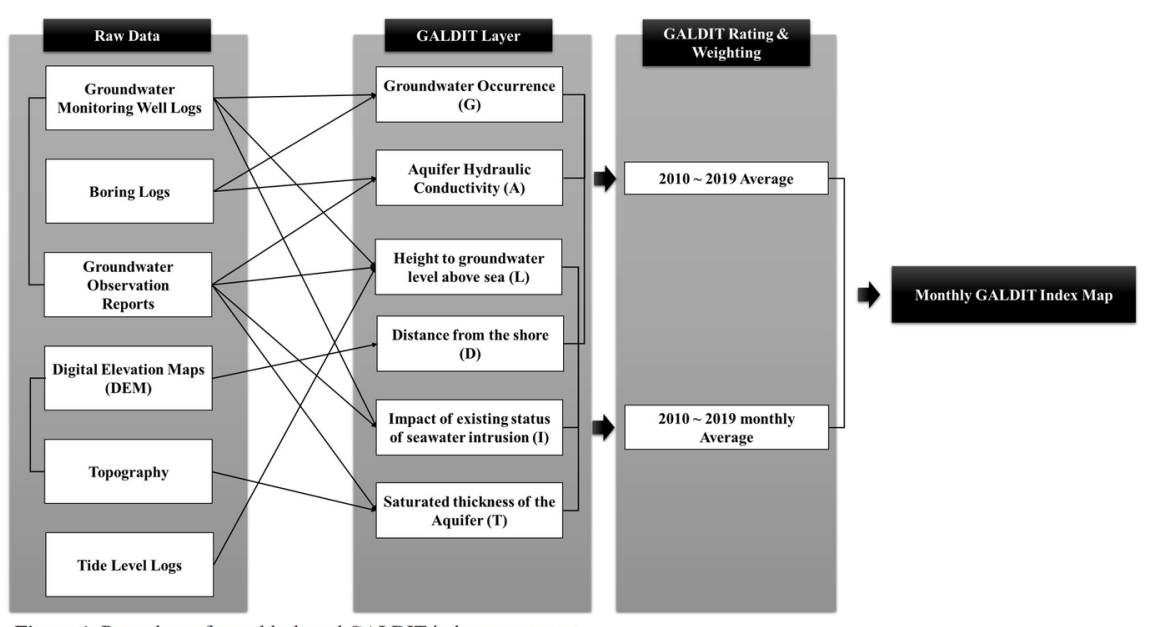

Figure 1. Procedure of monthly-based GALDIT index assessment

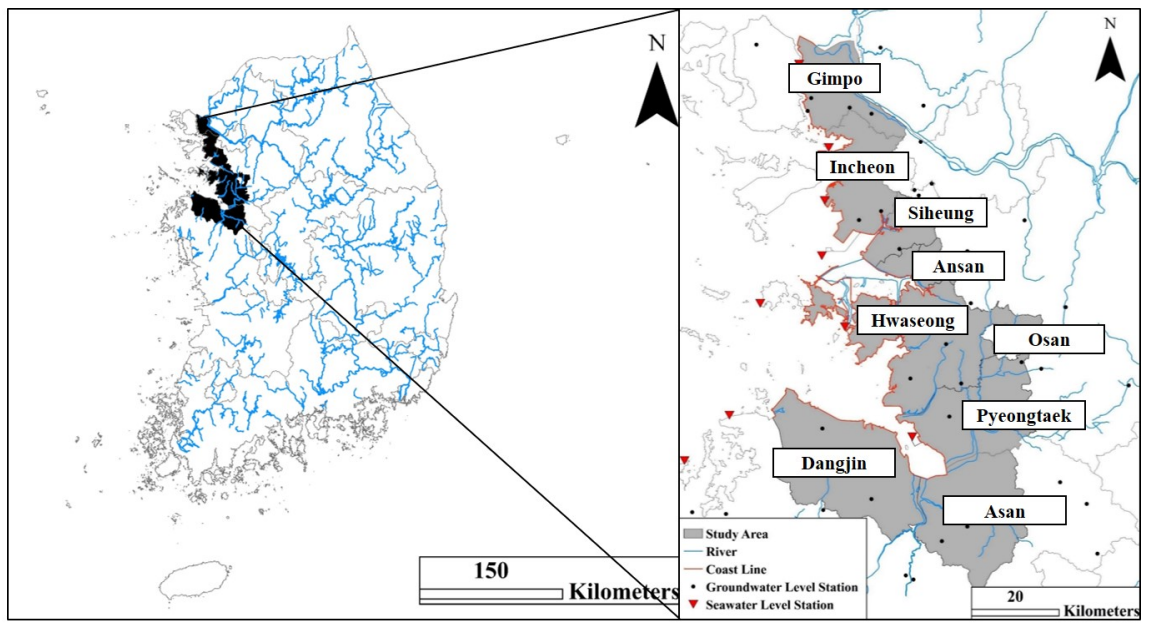

Figure 2. Study area in western coastal area of South Korea

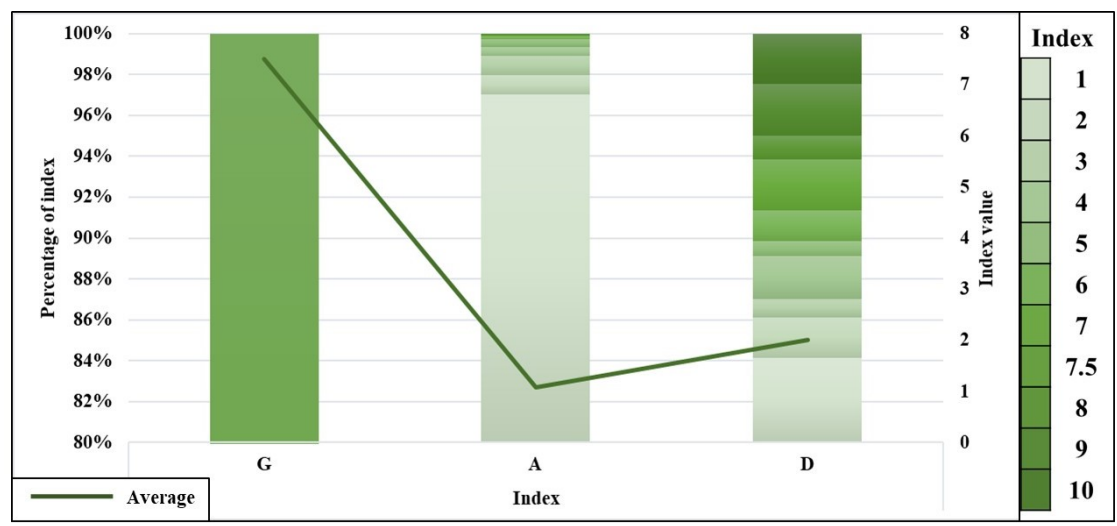

Figure 3. Distribution of static parameters' rating for groundwater occurrence $(G)$, aquifer hydraulic conductivity (A) and distance from the shore (D) 

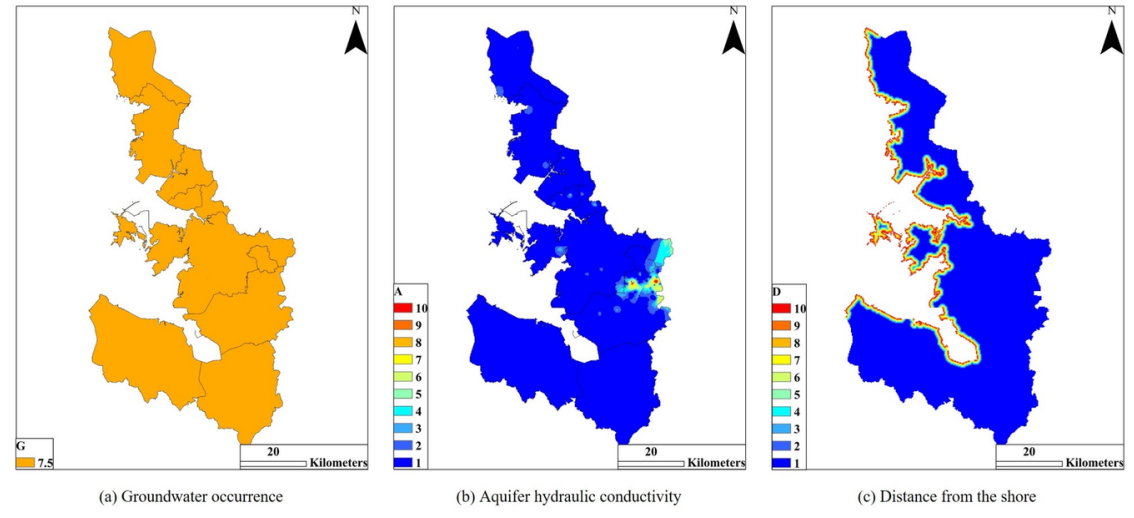

Figure 4. Thematic maps of static parameters' rating for groundwater occurrence (G), aquifer hydraulic conductivity (A) and distance from the shore (D)

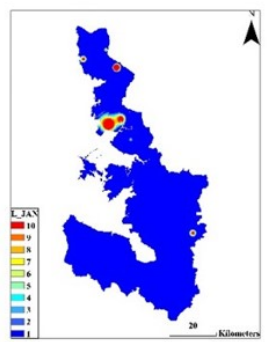

(a) JAN

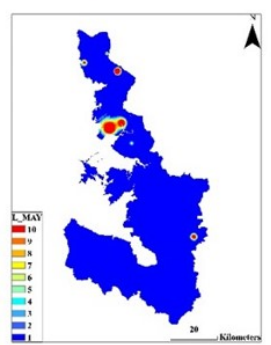

(e) MAY

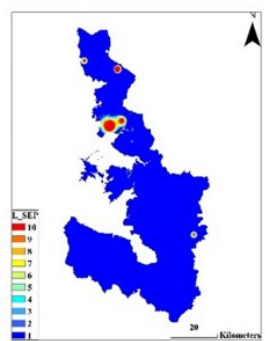

(i) SEP

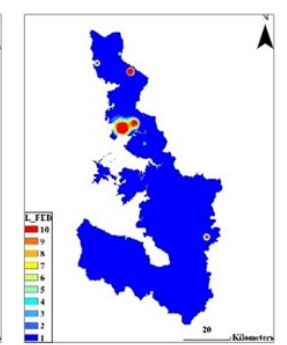

(b) FEB

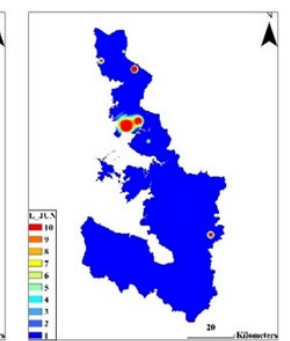

(f) JUN

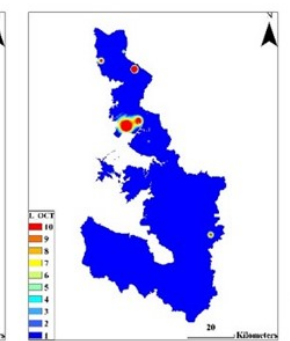

(j) $\mathrm{OCT}$

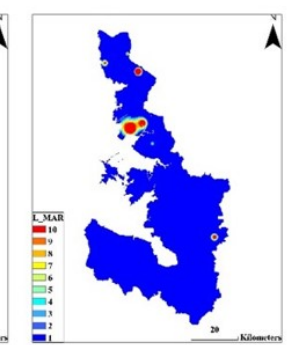

(c) MAR

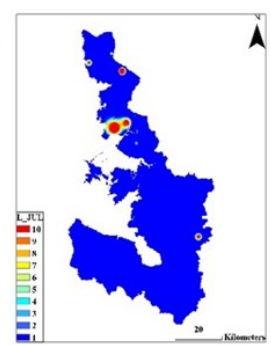

(g) JUL

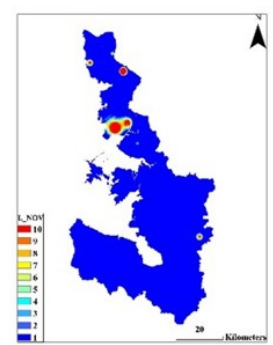

(k) NOV

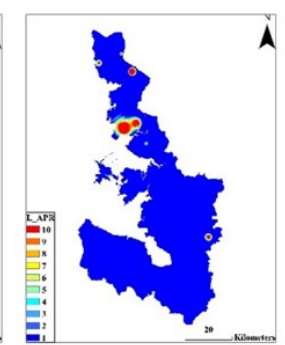

(d) APR

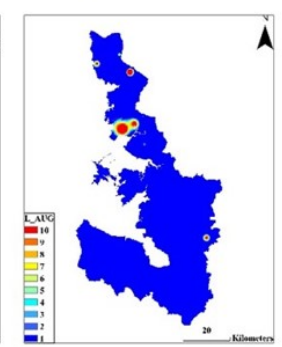

(h) AUG

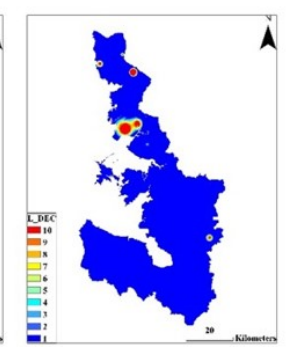

(1) DEC

Figure 5. Thematic maps of the dynamic parameter's rating for monthly height of groundwater level above sea level (L) 


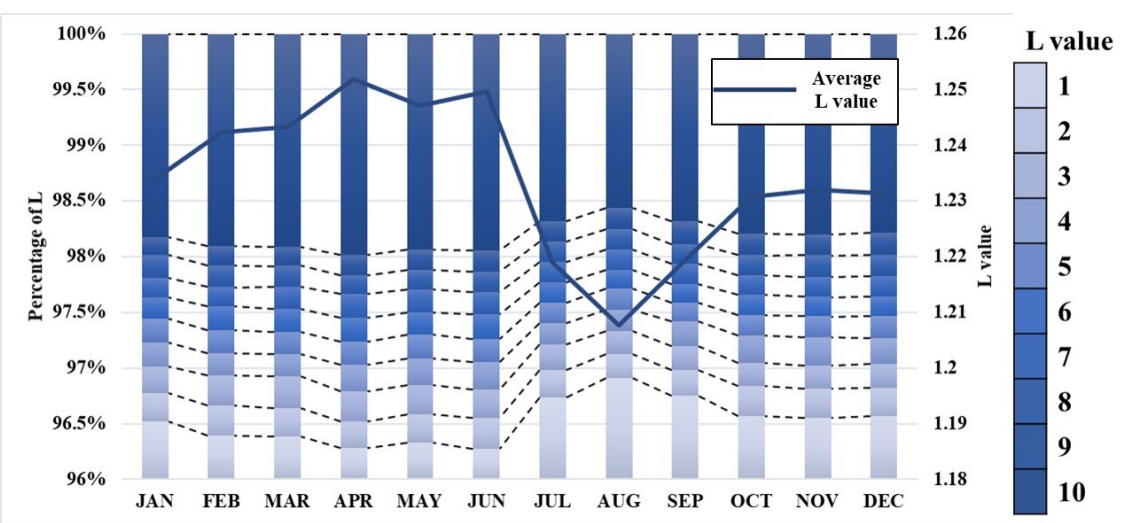

Figure 6. Distribution of the dynamic parameter's rating for monthly height of groundwater level above sea level (L)

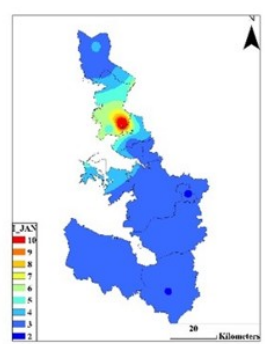

(a) JAN

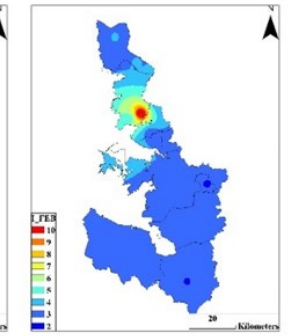

(b) FEB

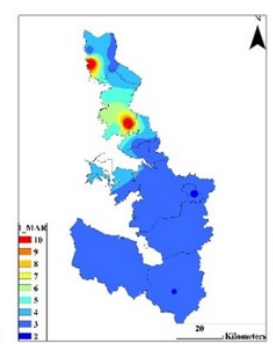

(c) MAR

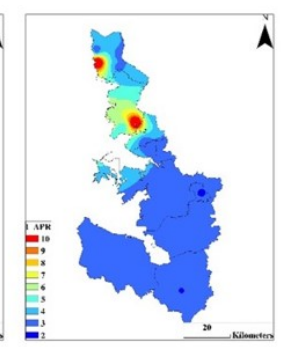

(d) APR

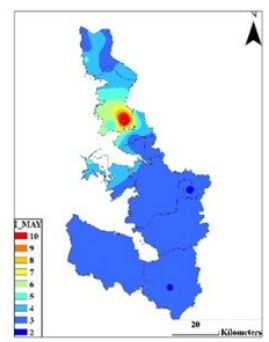

(e) MAY

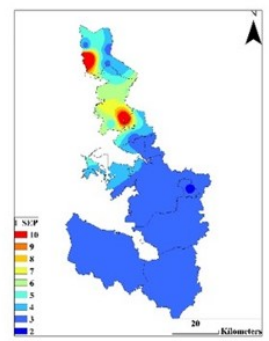

(i) SEP

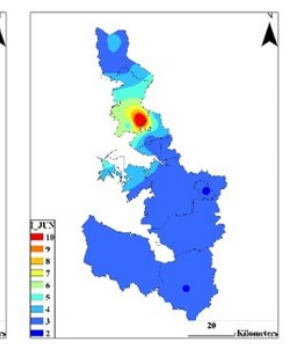

(f) JUN

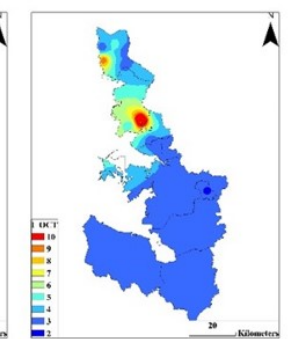

(j) OCT

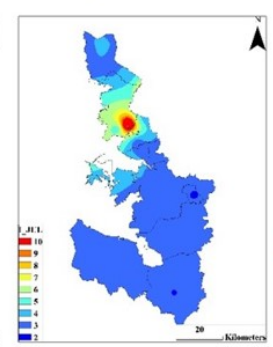

(g) JUL

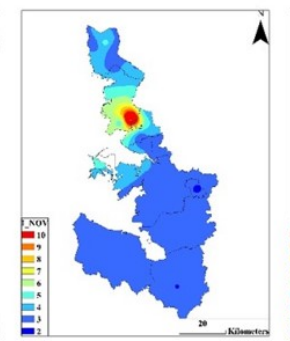

(k) NOV

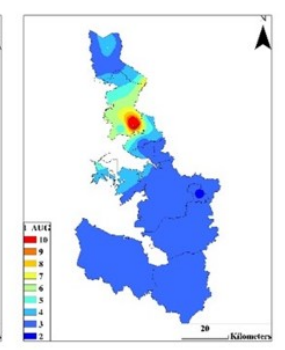

(h) AUG

Figure 7. Thematic maps of the dynamic parameter's rating for monthly impact of existing status of seawater intrusion (I) 


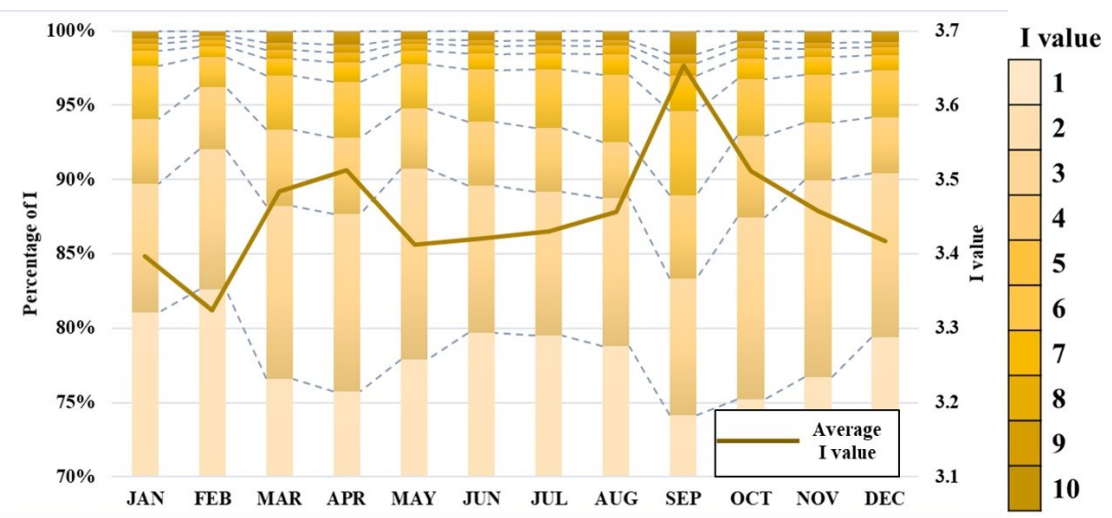

Figure 8. Distribution of the dynamic parameter's rating for monthly impact of existing status of seawater intrusion (I)

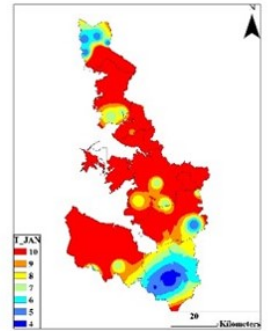

(a) JAN

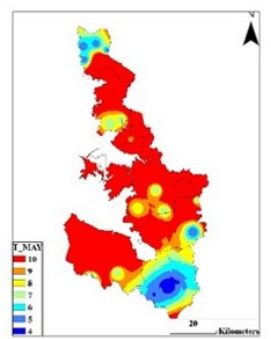

(e) MAY

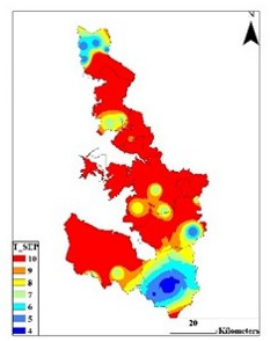

(i) SEP

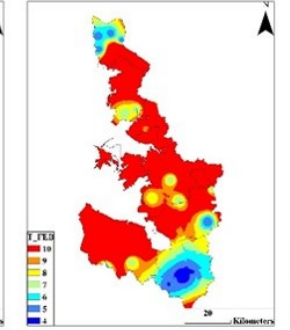

(b) FEB

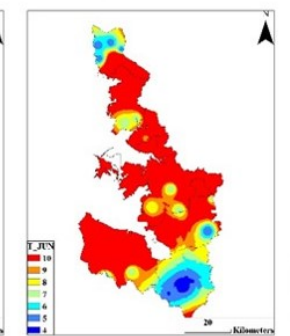

(f) JUN

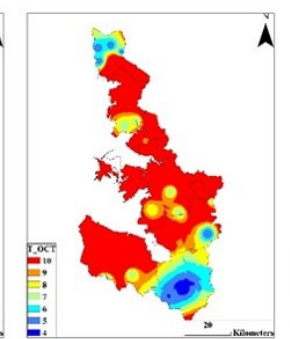

(j) OCT

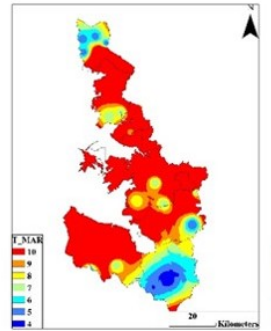

(c) MAR

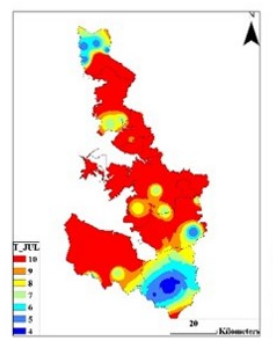

(g) JUL

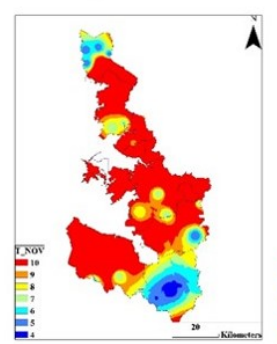

(k) NOV

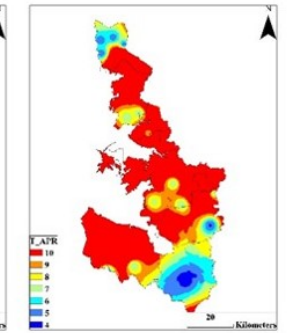

(d) APR

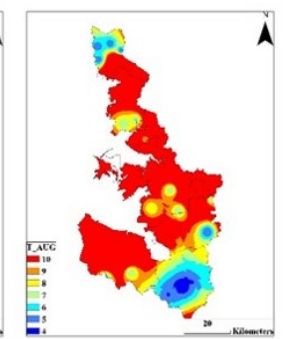

(h) AUG

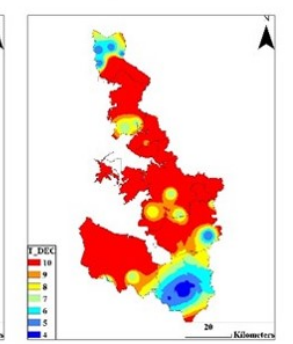

(1) DEC

Figure 9. Thematic maps of the dynamic parameter's rating for monthly saturated thickness of aquifer $(\mathrm{T})$ 


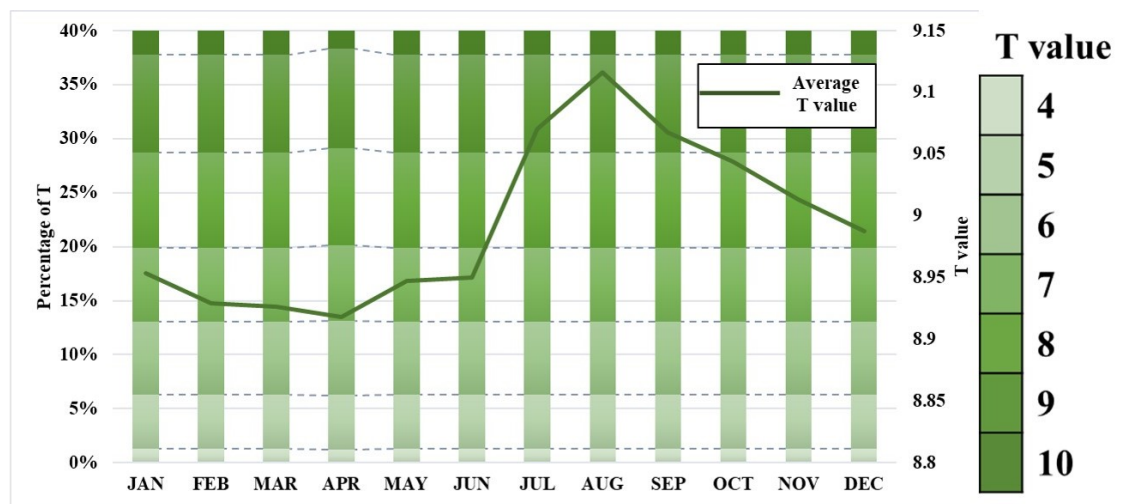

Figure 10. Distribution of the dynamic parameter's rating for saturated thickness of aquifer (T)

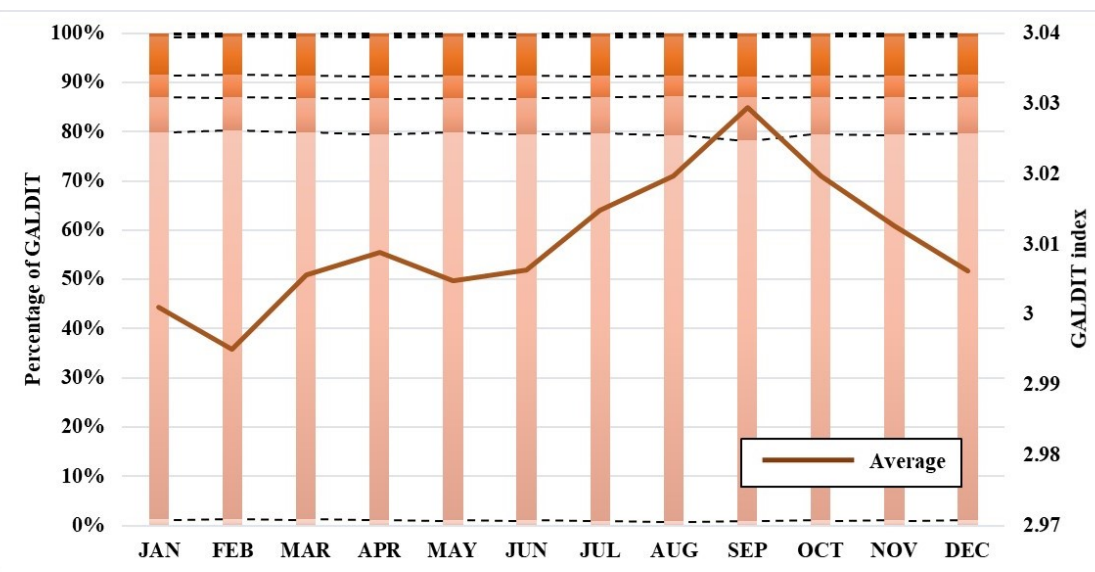

GALDIT index

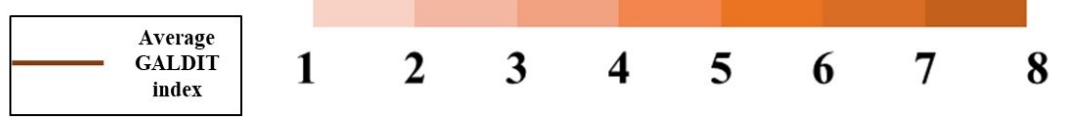

Figure 11. Distribution of monthly GALDIT index 


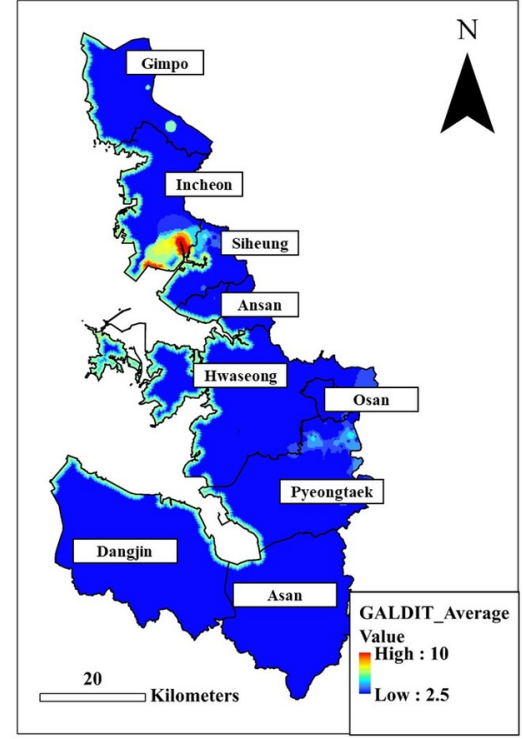

(a) Original GALDIT

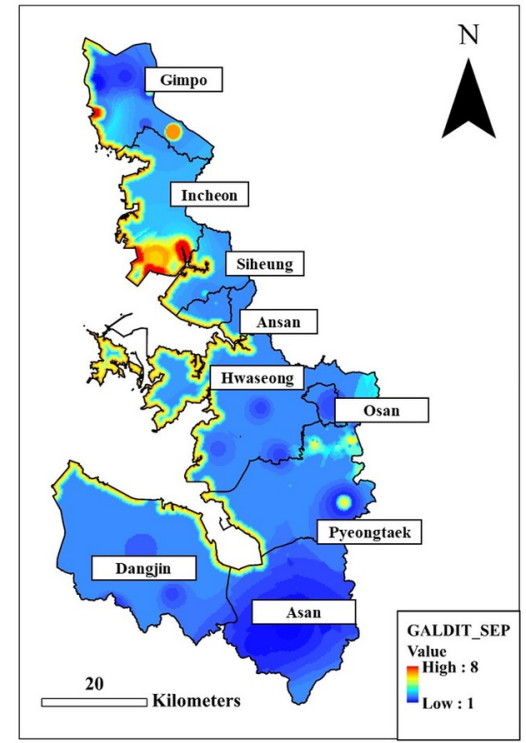

(b) Monthly GALDIT in September

Figure 12. A comparison between original GALDIT yearly average and monthly GALDIT in September 
Table 1. Theorical weights and rates for GALDIT

\begin{tabular}{|c|c|c|c|}
\hline Parameter & Weight & $\begin{array}{c}\text { GALDIT Factor Variable } \\
\text { Range }\end{array}$ & $\begin{array}{c}\text { Importance } \\
\text { Rating }\end{array}$ \\
\hline Groundwater occurrence & 1 & $\begin{array}{l}\text { Confined aquifer } \\
\text { Unconfined aquifer } \\
\text { Leaky confined aquifer } \\
\text { Bounded aquifer }\end{array}$ & $\begin{array}{c}10 \\
7.5 \\
5 \\
2.5\end{array}$ \\
\hline $\begin{array}{l}\text { Aquifer hydraulic } \\
\text { conductivity } \\
\text { (m/day) }\end{array}$ & 3 & $\begin{array}{c}>40 \\
10-40 \\
5-10 \\
<5\end{array}$ & $\begin{array}{c}10 \\
7.5 \\
5 \\
2.5\end{array}$ \\
\hline $\begin{array}{l}\text { Height of groundwater level } \\
\text { above sea level } \\
\text { (m) }\end{array}$ & 4 & $\begin{array}{c}<1.0 \\
1.0-1.5 \\
1.5-2.0 \\
>2.0\end{array}$ & $\begin{array}{c}10 \\
7.5 \\
5 \\
2.5\end{array}$ \\
\hline $\begin{array}{l}\text { Distance from the shore } \\
\text { (m) }\end{array}$ & 4 & $\begin{array}{c}<500 \\
500-700 \\
750-1000 \\
>1000\end{array}$ & $\begin{array}{c}10 \\
7.5 \\
5 \\
2.5\end{array}$ \\
\hline $\begin{array}{c}\text { Impact of existing status of } \\
\text { seawater intrusion } \\
(\mu \mathrm{s} / \mathrm{m})\end{array}$ & 1 & $\begin{array}{c}>3000 \\
2000-3000 \\
1000-2000 \\
<1000\end{array}$ & $\begin{array}{c}10 \\
7.5 \\
5 \\
2.5\end{array}$ \\
\hline $\begin{array}{l}\text { Saturated thickness of the } \\
\text { aquifer } \\
\text { (m) }\end{array}$ & 2 & $\begin{array}{c}>10 \\
7.5-10 \\
5-7.5 \\
<5\end{array}$ & $\begin{array}{c}10 \\
7.5 \\
5 \\
2.5\end{array}$ \\
\hline
\end{tabular}




\section{Table 2. Modified rates for GALDIT}

\begin{tabular}{|c|c|c|}
\hline Parameter & Modified Variable Range & $\begin{array}{c}\text { Modified Importance } \\
\text { Rating }\end{array}$ \\
\hline Groundwater occurrence & $\begin{array}{c}\text { Confined aquifer } \\
\text { Unconfined aquifer } \\
\text { Leaky confined aquifer } \\
\text { Bounded aquifer }\end{array}$ & $\begin{array}{c}10 \\
7.5 \\
5 \\
2.5\end{array}$ \\
\hline $\begin{array}{l}\text { Aquifer hydraulic } \\
\text { conductivity } \\
\text { (m/day) }\end{array}$ & $\begin{array}{c}>40 \\
34-40 \\
28-34 \\
22-28 \\
16-22 \\
10-16 \\
8-10 \\
6-8 \\
4-6 \\
<4\end{array}$ & $\begin{array}{l}10 \\
9 \\
8 \\
7 \\
6 \\
5 \\
4 \\
3 \\
2 \\
1\end{array}$ \\
\hline $\begin{array}{c}\text { Height of groundwater } \\
\text { level } \\
\text { above sea level } \\
\text { (m) }\end{array}$ & $\begin{array}{c}<1.0 \\
1.0-1.2 \\
1.2-1.4 \\
1.4-1.6 \\
1.6-1.8 \\
1.8-2.0 \\
2.0-2.2 \\
2.2-2.4 \\
2.4-2.6 \\
>2.6\end{array}$ & $\begin{array}{l}10 \\
9 \\
8 \\
7 \\
6 \\
5 \\
4 \\
3 \\
2 \\
1\end{array}$ \\
\hline $\begin{array}{l}\text { Distance from the shore } \\
\text { (m) }\end{array}$ & $\begin{array}{c}<500 \\
500-600 \\
600-700 \\
700-800 \\
800-900 \\
900-1000 \\
1000-1100\end{array}$ & $\begin{array}{l}10 \\
9 \\
8 \\
7 \\
6 \\
5 \\
4\end{array}$ \\
\hline
\end{tabular}


Table 3. A comparison between theoretical weight and effective weight

\begin{tabular}{|c|c|c|c|c|c|c|c|}
\hline \multirow{2}{*}{ Parameter } & \multirow{2}{*}{ Theoretical weight } & \multirow{2}{*}{ Theoretical weight (\%) } & \multirow{2}{*}{ RANK } & \multicolumn{3}{|c|}{ Effective weight (\%) } & \multirow{2}{*}{ RANK } \\
\hline & & & & $\min$ & $\max$ & mean & \\
\hline G & 1 & 6.67 & 5 & 6.44 & 26.11 & 17.63 & 2 \\
\hline $\mathrm{A}$ & 3 & 20 & 3 & 2.56 & 45.44 & 7.45 & 6 \\
\hline $\mathrm{L}$ & 4 & 26.67 & 1 & 4.82 & 59.82 & 10.53 & 4 \\
\hline $\mathrm{D}$ & 4 & 26.67 & 1 & 4.97 & 59.19 & 14.88 & 3 \\
\hline I & 1 & 6.67 & 5 & 3.42 & 21.62 & 7.87 & 5 \\
\hline $\mathrm{T}$ & 2 & 13.33 & 4 & 9.44 & 49.29 & 41.50 & 1 \\
\hline
\end{tabular}

